\title{
Effect of dexmedetomidine infusion on stress induced blood glucose levels and intraoperative sevoflurane requirement
}

\author{
Yasha V Kameshwar ${ }^{1, *}$, M R Upadhyay ${ }^{2}$ \\ ${ }^{1}$ Ex-Student, ${ }^{2}$ Professor and HOD, Dept. of Anaesthesiology, SSG Hospital and Baroda Medical College, Vadodara, Gujarat, \\ India
}

*Corresponding Author: Yasha V Kameshwar

Email: yasha.vdk@gmail.com

Received: $14^{\text {th }}$ September, 2018

Accepted: $3^{\text {rd }}$ November, 2018

\begin{abstract}
Introduction: Dexmedetomidine has been shown to blunt the stress response to surgery and reduce the consumption of inhalational anaesthetic agents. Hence, we designed this study to observe the effects of IV Dexmedetomidine infusion on stressinduced blood glucose levels and intra operative Sevoflurane requirement during laparoscopic surgery.

Materials and Methods: Sixty patients between the ages of 18-60 years, of either gender, ASA Grade I \& II, posted for elective laparoscopic surgical procedures under general anaesthesia were divided into two groups of 30 each. Group D received loading dose of Inj. Dexmedetomidine at $1 \mu \mathrm{g} / \mathrm{kg}$ diluted to $50 \mathrm{ml}$ and given over 10 minutes; followed by maintenance with $0.5 \mu \mathrm{g} / \mathrm{kg} / \mathrm{hour}$, till the end of surgery. Group P received similar volume of normal saline. Anaesthesia was maintained with Nitrous oxide in oxygen (50:50) and Sevoflurane keeping BIS 40 - 60. Serial blood glucose levels, sevoflurane requirement by Dion's method, extubation time, sedation score and adverse effects were observed. The data was analyzed using student $t$ test.

Results: Blood glucose levels at first hour post operatively in group $\mathrm{P}$ and in group D, were $136.7 \pm 6.30 \mathrm{mg} / \mathrm{dl}$ and $103.8 \pm 8.28$ $\mathrm{mg} / \mathrm{dl}$ respectively $(\mathrm{P}<0.0001)$. There was $27.07 \%$ rise in group $\mathrm{P}$ and $2.89 \%$ fall in group $\mathrm{D}$ from baseline value. Mean first hourly Sevoflurane consumption in group $\mathrm{P}$ and in group D were $11.22 \pm 1.14 \mathrm{ml}$ and $8.34 \pm 0.88 \mathrm{ml}$ respectively ( $<<0.0001$ ) (25.61\% reduction in group D).

Conclusion: IV Dexmedetomidine infusion was effective in attenuating stress induced blood glucose levels and it also reduced Sevoflurane requirement without affecting the time for extubation.
\end{abstract}

Keywords: Dexmedetomidine, Stress induced blood glucose levels, Dion's method, Sevoflurane consumption.

\section{Introduction}

Alpha $(\alpha)$-2 adrenergic receptor (AR) agonists are the centre of interest in Anaesthesiology since last two decades for their sedative, anxiolytic, analgesic and sympatholytic properties. ${ }^{1,2}$ The first member of this group; Clonidine; which was introduced in 1960 as nasal decongestant, was later used as an adjuvant for general as well as regional anaesthesia. ${ }^{1,2}$ After the discovery of Clonidine, a more potent $\operatorname{Alpha}(\alpha)-2$ agonist Medetomidine; ${ }^{3}$ and its stereoisomer Dexmedetomidine were discovered.

Dexmedetomidine has been described as a 'Wonder Drug' ${ }^{4}$ due to its multiple roles in anaesthesia practise.

Stress response to surgery and anaesthesia is not only manifested as changes in pulse rate and blood pressure but also by metabolic, neurohormonal and immunological changes. ${ }^{5,6}$ Therefore, various indicators like blood glucose, serum cortisol, Interleukin-6, plasma nor-epinephrine levels have been used to quantify the stress response and their attenuation by dexmedetomidine has been demonstrated. ${ }^{7,8}$

In addition to its analgesia sparing property; $;, 10$ intravenous administration of Dexmedetomidine during general anaesthesia is reported to decrease the minimum alveolar concentration (MAC) and intraoperative requirement of volatile anaesthetic agents. ${ }^{11}$
This clinical study; therefore, aims to demonstrate the effect of intravenous Dexmedetomidine administration on stress induced blood glucose levels and intra operative Sevoflurane requirement. It also includes assessment of perioperative hemodynamic stability, time for tracheal extubation and post operative sedation levels.

\section{Materials and Methods}

After obtaining institutional ethical and scientific research committee approval; this prospective, randomised, single blind, placebo-controlled clinical trial was conducted in department of Anaesthesiology, Government Medical College and SSG Hospital Vadodara during November 2014 to November 2015. 60 patients of age group 18 to 60 years, of either gender, American Society of Anaesthesiologists (ASA) grade I and II, posted for laparoscopic intra-peritoneal surgeries of 1-2 hours duration with minimal expected blood loss were enrolled. Patients on $\alpha-2$ agonists or antagonists, $\beta$ blockers, calcium channel blockers, digoxin or any other anti hypertensive agent, psycho active medications, pregnant and breast feeding mothers, ASA grade III or IV patients and those unwilling to participate in the study were excluded. After thorough pre anaesthetic check up and routine investigations, selected patients were informed about the motto of our study in local language and a written 
informed consent was taken after ensuring their willingness to participate in the study.

After ensuring adequate fasting, patient was shifted to operation theatre, multipara monitor was attached to note the baseline pulse rate, blood pressure, spo2; and BIS, attached to note baseline consciousness. 18G IV cannula was secured and Ringer Lactate at $5 \mathrm{ml} / \mathrm{kg} /$ hour was started. All patients received premedication Inj. Glycopyrrolate $0.2 \mathrm{mg} / \mathrm{i} . \mathrm{m} 45$ minutes before surgery; and before induction, Inj. Ondansetron $4 \mathrm{mg} / \mathrm{i} . \mathrm{v}, \mathrm{Inj}$.
Ranitidine 50mg/ i.v, Inj. Fentanyl $2 \mathrm{mcg} / \mathrm{kg} /$ i.v were given. Patients were randomly divided (Randomisation by computer method using www.randomiser.org) into 2 groups: Group (D) patients received loading dose of Inj.Dexmedetomidine $1 \mu \mathrm{g} / \mathrm{kg} / 10 \mathrm{~min}$ diluted to $50 \mathrm{ml}$ with Normal Saline, given before induction, followed by maintenance dose $0.5 \mu / \mathrm{kg} / \mathrm{hour}$ till the end of surgery; and Group $(\mathrm{P})$ patients received Normal Saline in a similar manner.

Table 1: Dexmedetomidine loading dose and maintenance dose calculation

\begin{tabular}{|c|c|c|c|c|c|}
\hline $\begin{array}{c}\text { Actual } \\
\text { weight(kg) }\end{array}$ & $\begin{array}{c}\text { Taken } \\
\text { weight } \\
\text { as(kg) }\end{array}$ & \multicolumn{2}{|c|}{$\begin{array}{c}\text { Loading Dose } \\
\text { (Given over 10 minutes) }\end{array}$} & \multicolumn{2}{|c|}{ Maintenance Dose } \\
\cline { 3 - 6 } & & $\begin{array}{c}\text { Dose of } \\
\text { Dex( } \boldsymbol{\mu g})\end{array}$ & $\begin{array}{c}\text { Infusion } \\
\text { volume(m) }\end{array}$ & $\begin{array}{c}\text { Dose of } \\
\text { Dex( } \boldsymbol{\mu g})\end{array}$ & $\begin{array}{c}\text { Infusion rate } \\
(\mathbf{m l} / \mathbf{h r})\end{array}$ \\
\hline $41-45$ & 40 & 40 & 10 & 20 & 5 \\
$46-50$ & 50 & 50 & 12.5 & 25 & 6.25 \\
$51-55$ & 50 & 50 & 12.5 & 25 & 6.25 \\
$56-60$ & 60 & 60 & 15 & 30 & 7.5 \\
$61-65$ & 60 & 60 & 15 & 30 & 7.5 \\
$66-70$ & 70 & 70 & 17.5 & 35 & 8.75 \\
\hline
\end{tabular}

\section{Syringe infusion pump}

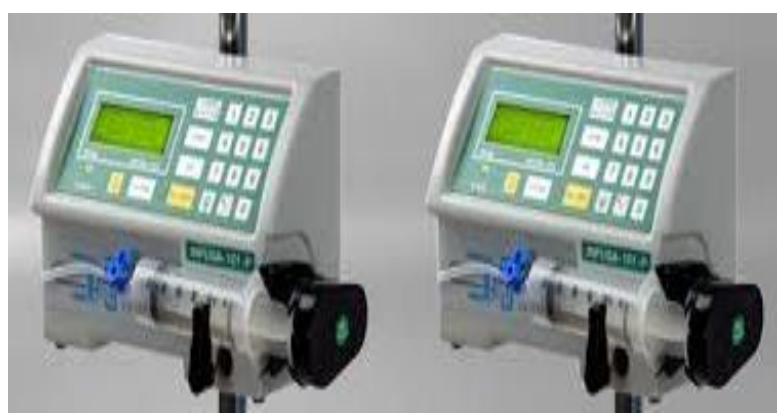

Patients were pre oxygenated for 3 minutes with $100 \%$ oxygen, Inj. Propofol $1.5 \mathrm{mg} / \mathrm{kg}$ given as boluses of 20-30mg till loss of eyelash reflex response and BIS dropped to 50. Inj. Succinyl choline $1.5 \mathrm{mg} / \mathrm{kg} / \mathrm{i} . v$ given and ventilation continued. Once fasciculation disappeared from toes, patients were intubated with appropriate size cuffed portex endotracheal tube. Tube connected to Bain's circuit, bilateral equal air entry confirmed and tube was fixed adequately. Anaesthesia was maintained with nitrous oxide in oxygen (50:50), at 3Litres/minute, with Inj. Vecuronium bromide $0.1 \mathrm{mg} / \mathrm{kg}$ as loading dose and $0.025 \mathrm{mg} / \mathrm{kg}$ as top-up when required (last dose 25 minutes before expected completion of surgery) and Sevoflurane titrated to maintain BIS 40-60. Anaesthesia machine Drager Fabius was used. End tidal carbon dioxide $\left(\mathrm{EtCO}_{2}\right)$ and intra abdominal pressure were maintained between 35$45 \mathrm{~mm}$ of $\mathrm{Hg}$ and $12-14 \mathrm{~mm}$ of $\mathrm{Hg}$ respectively. At the end of surgery nitrous oxide, Sevoflurane, Inj. Dexmedetomidine infusion was stopped. Patient was ventilated with $100 \%$ oxygen till onset of respiratory efforts, after which reversal of residual neuro muscular blockade was done with Inj. Neostigmine $50 \mathrm{mcg} / \mathrm{kg}$ i.v and Inj. Glycopyrrolate $10 \mathrm{mcg} / \mathrm{kg}$ i.v. Extubation was done after ensuring adequate response to verbal commands, breathing effort and muscle tone. Patient was then shifted to recovery room (PACU).

Blood glucose levels were measured from patient's fresh capillary whole blood using glucose strip test ${ }^{8}$ at following intervals: Baseline (before Dexmedetomidine bolus), 30 minutes after intubation, $1^{\text {st }}$ and $2^{\text {nd }}$ hour post operatively. Hourly Sevoflurane requirement was calculated by Dion's method as follows: Usage of volatile anaesthetic agent $(\mathrm{ml})=$ Dialed concentration (\%) $\mathrm{x}$ duration at set concentration (min) $\mathrm{x}$ Total fresh gas flow (litre/min) x Molecular mass (mg) / 2412 x Density $(\mathrm{g} / \mathrm{ml}){ }^{12}$ The fixed values in this formula include- Total FGF (3 ltr /min), Molecular mass of Sevoflurane $(200.055 \mathrm{mg})$ and Density of Sevoflurane at $21^{\circ} \mathrm{C}(1.52 \mathrm{~g} / \mathrm{ml})$. The changing values were Dialed concentration and Duration at set concentration. Substituting the fixed values, this equation can be rewritten as: Amount of liquid Sevoflurane used $(\mathrm{ml})=$ 0.00273PT, $(\mathrm{P}=$ Dialed concentration, $\mathrm{T}=$ Time in seconds). ${ }^{13}$ Patient's pulse rate (bpm), oxygen saturation (\%), systolic and diastolic blood pressure $(\mathrm{mm}$ of $\mathrm{Hg}$ ) were noted at following intervals: Baseline (before bolus), 10 minutes after bolus, 1 minute after induction, after laryngoscopy and intubation, post pneumoperitoneum (PP) at $0,15,30,45,60,75,90$, 105, 120 minutes and post extubation (PE) at $0,15,30$, 60 and 120 minutes respectively.

The time for tracheal extubation was taken from stoppage of anaesthetic agents and Dexmedetomidine to the time when patient was extubated. Ramsay sedation score (table 2) at 0 and $60^{\text {th }}$ minute post extubation was 
noted. Duration of surgery and anaesthesia were recorded.

Table 2: Ramsay sedation score

\begin{tabular}{|l|r|}
\hline \multicolumn{1}{|c|}{ Score } & Response \\
\hline 1 & Anxious or restless or both \\
\hline 2 & Co operative, oriented and tranquil \\
\hline 3 & Responding to commands only \\
\hline 4 & Brisk response to light glabellar tap or loud auditory stimulus \\
\hline 5 & Sluggish response to light glabellar tap or loud auditory stimulus. \\
\hline 6 & Patient exhibits no response. \\
\hline
\end{tabular}

Adverse effects were noted and adequately treated as shown in table 3 .

Table 3: Definition of Adverse effects and their management

\begin{tabular}{|l|c|}
\hline \multicolumn{1}{|c|}{ Adverse effects } & Treatment \\
\hline $\begin{array}{l}\text { Bradycardia (PR }<50 \mathrm{bpm} \text { or Fall in PR> 20\% } \\
\text { from baseline value) }\end{array}$ & Inj.Atropine 0.6mg IV \\
\hline $\begin{array}{l}\text { Tachycardia (PR }>120 \mathrm{bpm} \text { or Increase in PR> } \\
20 \% \text { from baseline value) }\end{array}$ & $\begin{array}{c}\text { Increase in Sevoflurane concentration. } \rightarrow \text { Inj. } \\
\text { Metoprolol 5 mg IV }\end{array}$ \\
\hline $\begin{array}{l}\text { Hypotension (SBP }<80 \mathrm{~mm} \text { of } \mathrm{Hg} / \mathrm{Fall} \text { in SBP } \\
>20 \% \text { from baseline value) }\end{array}$ & $\begin{array}{c}\text { Reduce inspired Sevoflurane conc. } \rightarrow \text { 200ml fluid } \\
\text { bolus } \rightarrow \text { Inj. Ephedrine 5-10 mg bolus. }\end{array}$ \\
\hline $\begin{array}{l}\text { Hypertension (SBP }>140 \mathrm{~mm} \text { of } \mathrm{Hg} \text { or rise in } \\
\text { SBP }>20 \% \text { from baseline value) }\end{array}$ & $\begin{array}{c}\text { Increase inspired Sevoflurane conc. } \rightarrow \text { Inj. } \\
\text { Nitroglycerine IV infusion }\end{array}$ \\
\hline Nausea / vomiting & Inj. Metochlopromide 10 mg IV \\
\hline Heavy Sedation (RSS 4 or more) & Oxygenation \\
\hline Dryness of mouth & Wetting of lips \\
\hline
\end{tabular}

\section{Statistics}

Sample size was calculated using 'blood glucose levels' as primary criteria, ${ }^{14}$ (In our reference paper, significant difference in mean blood glucose levels was observed during $1^{\text {st }}$ hour post-operatively) with confidence interval 95\% ( $\alpha$ error 0.05 ), power $90 \%$ ( $\beta$ error 0.1 ) was 20 in each group. For better sensitivity we included a total of 60 patients with 30 in each group. Statistical-analysis was done using Medcalc software 12.5.0.0 version, with T-test and Chi-square test used for parametric and non-parametric data respectively and results expressed as mean \pm SD. $P$ value less than 0.05 was considered as statistically significant $(*)$, less than 0.01 was highly significant $(* *)$ and values $<0.001$ was very highly significant $(* * *)$.

\section{Results}

Both the groups were comparable with respect to demographic data like age, gender, body weight, ASA grade, duration of surgery and anaesthesia.

Table 4: Demographic data

\begin{tabular}{|c|c|c|c|}
\hline Parameters & Group P & Group D & P value \\
\hline Age $(\mathrm{yr})($ mean \pm SD \& range $)$ & $\begin{array}{l}38.77 \pm 10.15 \\
\quad(21-56)\end{array}$ & $\begin{array}{l}35.73 \pm 11.18 \\
\quad(19-60)\end{array}$ & $>0.05$ \\
\hline $\begin{array}{l}\text { Gender: Male } \\
\text { Female } \\
\text { No. Of patients }(\%)\end{array}$ & $\begin{array}{l}18(60 \%) \\
12(40 \%)\end{array}$ & $\begin{array}{l}15(50 \%) \\
15(50 \%)\end{array}$ & $>0.05$ \\
\hline $\begin{array}{l}\text { Weight }(\mathrm{kg}) \\
(\text { mean } \pm \mathrm{SD} \text { \&range })\end{array}$ & $\begin{array}{c}60.1 \pm 5.50 \\
(50-73)\end{array}$ & $\begin{array}{c}58.37 \pm 6.25 \\
(40-68)\end{array}$ & $>0.05$ \\
\hline $\begin{array}{l}\text { ASA: } 1 \\
2 \\
\text { No. Of patients }(\%)\end{array}$ & $\begin{array}{l}21(70 \%) \\
9(30 \%)\end{array}$ & $\begin{array}{c}23(76.6 \%) \\
7(23.3 \%)\end{array}$ & $>0.05$ \\
\hline $\begin{array}{l}\text { Duration of surgery (min) } \\
(\text { mean } \pm \text { SD) }\end{array}$ & $97.33 \pm 6.21$ & $97.93 \pm 5.03$ & $>0.05$ \\
\hline $\begin{array}{l}\text { Duration of anaesthesia (min) } \\
(\text { mean } \pm \text { SD) }\end{array}$ & $110.76 \pm 5.06$ & $109.06 \pm 4.01$ & $>0.05$ \\
\hline
\end{tabular}


The blood glucose level was very highly significantly $(\mathrm{p}<0.0001)$ lower in Group D as compared to Group $\mathrm{P}$ at all intervals except baseline. Laryngoscopy and intubation caused a rise in blood glucose levels by $45.2 \%$ in group $\mathrm{P}$, while the rise was $9.69 \%$ in group D. $1^{\text {st }}$ hour post operatively, the blood glucose level was $27.07 \%$ higher than the baseline in group $\mathrm{P}$, but group D showed $2.89 \%$ fall from the baseline value. $2^{\text {nd }}$ hour post operatively, the blood glucose level remained $11.05 \%$ higher than the baseline value in group $\mathrm{P}$, but group $\mathrm{D}$ showed a reduction by $0.25 \%$ (Fig. 1)

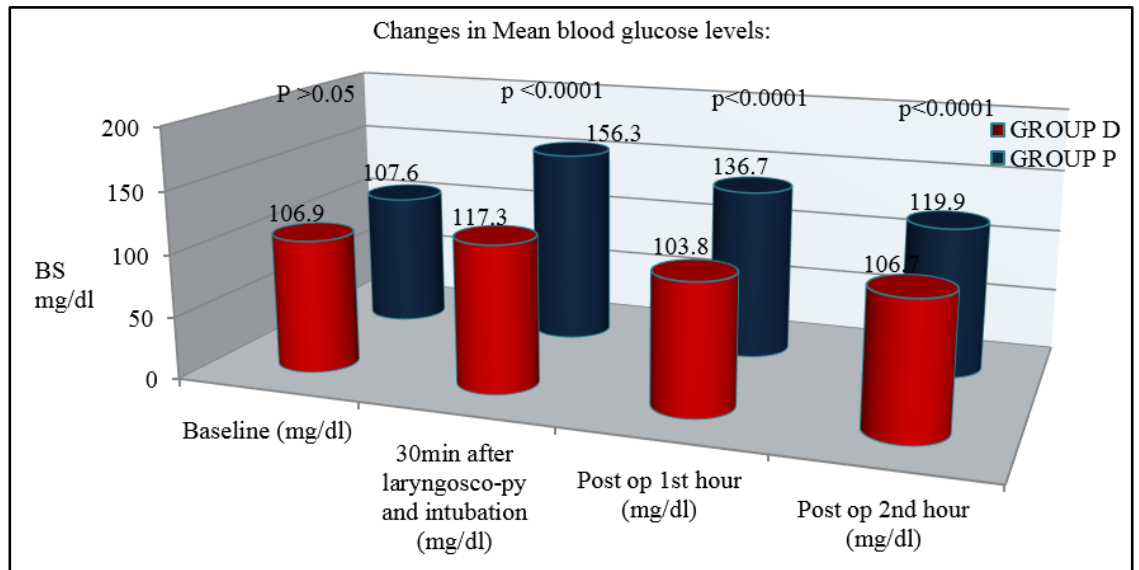

Fig. 1: Changes in mean blood glucose levels

Compared to Group P, Group D patients showed statistically significant reduction in hourly Sevoflurane requirement, as calculated by Dion's formula $(\mathrm{p}<0.0001)$. There was $25.61 \%$ and $21.47 \%$ reduction in Sevoflurane requirement during $1^{\text {st }}$ and $2^{\text {nd }}$ hour in Group D as compared to Group P. (Fig. 2)

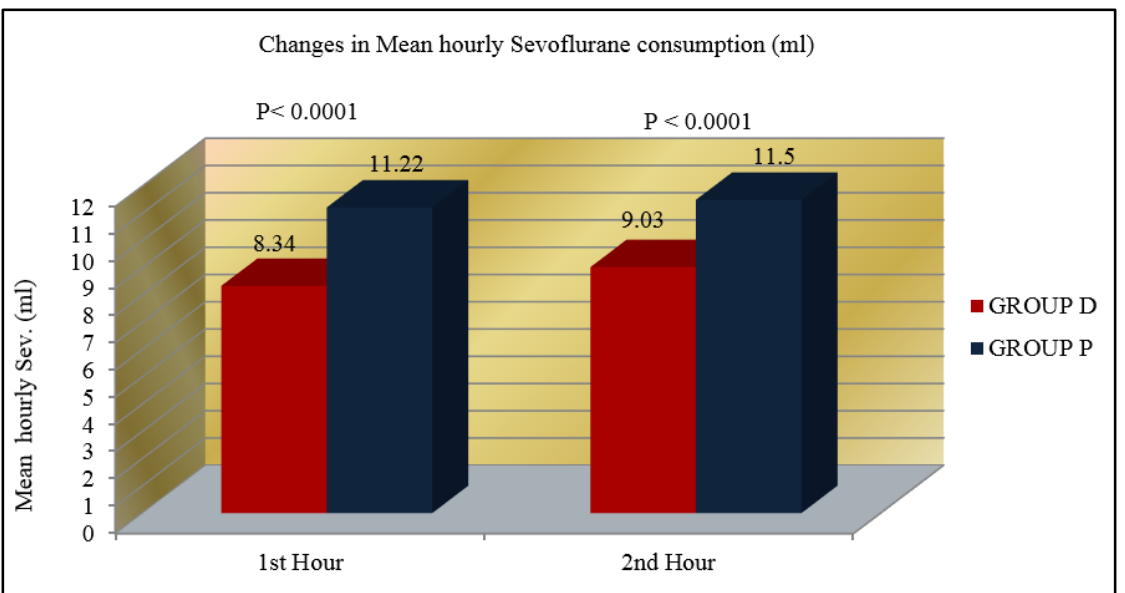

Fig. 2: Changes in mean hourly sevoflurane consumption (ml)

Mean pulse rate was very highly significantly lower in group D from 10 minutes after bolus to $75^{\text {th }}$ minute post pneumoperitoneum $(\mathrm{p}<0.0001)$, thereafter till $30^{\text {th }}$ minute post extubation it remained significantly lower in Group D $(\mathrm{p}<0.05)$. Critical events like laryngoscopy, intubation and pneumoperitoneum caused some rise in pulse rate compared to post induction values in Group D, but the values were still highly significantly lower than Group P ( $\mathrm{p}<0.01)$. (Fig. 3) 


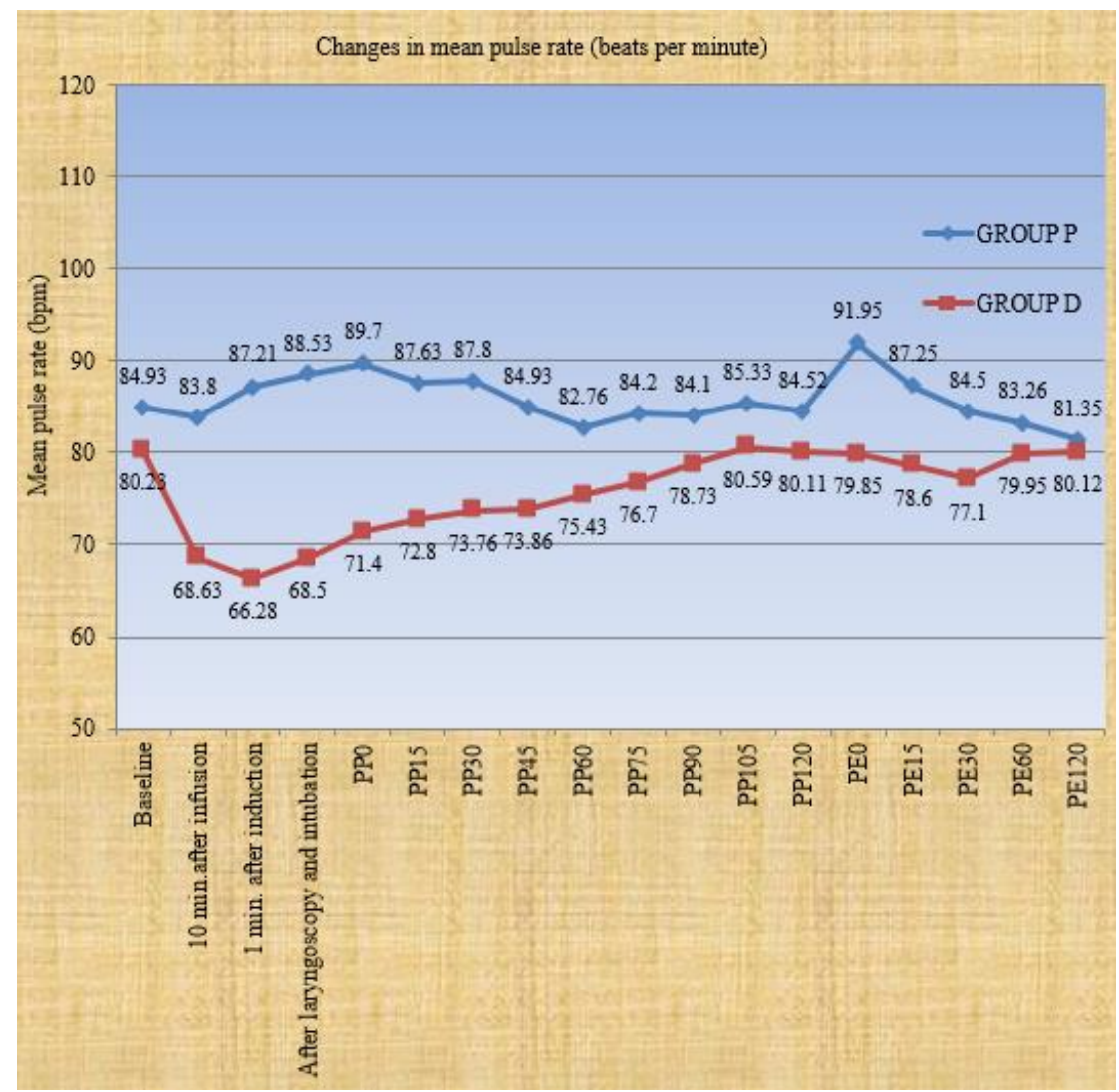

Fig. 3: Changes in mean pulse rate (bpm)

Tracheal extubation time and mean Ramsay Sedation scores were comparable in both the groups $(\mathrm{p}>0.05)$

Table 5: Extubation time and Post - operative mean Ramsay sedation scores (mean \pm SD)

\begin{tabular}{|l|c|c|c|}
\hline \multicolumn{1}{|c|}{ Parameter } & Group P & Group D & P value \\
\hline Extubation time (min) & $5.36 \pm 1.17$ & $5.83 \pm 1.09$ & $>0.05$ \\
\hline $\begin{array}{l}\text { Mean Ramsay sedation score } \\
\text { Post operative }\end{array}$ & \\
\hline 0 minute & $3.52 \pm 0.53$ & $3.11 \pm 0.40$ & $>0.05$ \\
\hline 60 minutes & $3.83 \pm 0.21$ & $3.54 \pm 0.52$ & $>0.05$ \\
\hline
\end{tabular}

The incidence of various adverse effects was comparable in both the groups. (Fig. 4)

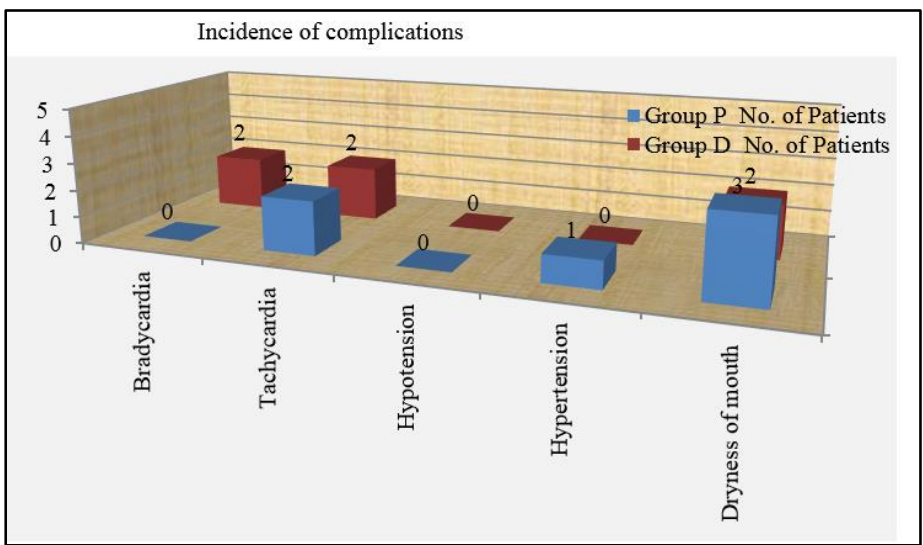

Fig. 4: Incidence of complications 
Bradycardia was observed in two patients in group $\mathrm{D}$, which was relieved by Inj.Atropine $0.6 \mathrm{mg}$ i.v, while Hypertension was observed in one patient of group P; though, not persistent.

\section{Discussion}

Laparoscopic surgeries are preferred now-a-days due to its various advantages like less trauma, less pain, quicker recovery and shorter hospital stay; hence we selected this surgery for the study. Anaesthesia and surgical procedures like laryngoscopy, intubation, extubation, reverse Trendelenburg patient positioning, pneumo peritoneum, carbon di oxide insufflation are associated with stress response (Dr. Manorama Singh 2003). ${ }^{5}$ This causes neuroendocrine, cytokine release which increases catecholamine and steroid levels, with predictable metabolic consequences (O'Riain SC et al 2005). ${ }^{15}$

Stimulation of hypothalamus, during stress, responds by causing ACTH release, resulting in sudden increase in cortisol. ${ }^{6}$ This rapidly mobilises the amino acids, fat; to form glucose, causes insulin resistance; thereby increasing blood glucose upto 50\% above normal, ${ }^{5}$ making glucose available for energy and synthesis of other compounds needed by different tissues. ${ }^{16}$ Hence, estimation of blood glucose serves to be a reliable indicator for indirect assessment of stress response and its modulation by pharmacological agents like alpha-2 agonists. ${ }^{8}$

Though such stress response is considered as homeostatic defence mechanism for adaptation and developing resistance to noxious stimuli, the continuous hyper metabolic state may result in exhaustion of essential components of the body causing fatigue, decreased resistance, delayed ambulation and increased morbidity and mortality. ${ }^{5,6}$ It could also be life threatening to patients with co morbidities like obesity, hypertension, diabetes mellitus, renal insufficiency, liver disease, geriatric age group.

Alpha-2 receptor agonists including Clonidine and Dexmedetomidine have been extensively used in clinical practice. Dexmedetomidine differs from
Clonidine in two aspects - one, it is more potent and receptor specific and secondly it is easy to titrate. ${ }^{17}$

Higher doses of Dexmedetomidine have been found to produce adverse biphasic cardiac response i.e. hypertension followed by hypotension, ${ }^{18}$ while very low doses fail to attenuate stress response to critical events. ${ }^{19}$ Dexmedetomidine has been used as single bolus dose as well as bolus followed by infusion..$^{20,21}$ Keniya VM et al $2011^{22}$ found that Dexmedetomidine infusion in a dose of $1 \mathrm{mcg} / \mathrm{kg}$ over 10 minutes followed by infusion of $0.2-0.7 \mathrm{mcg} / \mathrm{kg} / \mathrm{hr}$ can attenuate sympatho-adrenal response to tracheal intubation. Gupta K et al $2013^{8}$ used a single bolus dose of IV dexmedetomidine given in 10 minutes before induction while Harsoor SS et al $2014^{14}$ and Yacout AG et al $2012{ }^{7}$ used Dexmedetomidine in a loading dose of $1 \mathrm{mcg} / \mathrm{kg}$ over 10 minutes before induction followed by $0.5 \mathrm{mcg} / \mathrm{kg} / \mathrm{hr}$ till end of surgery. Since the distribution half life of Dexmedetomidine is about 9 minutes and the drug should be infused slowly to avoid the biphasic response, we also used similar dose schedule as used by Harsoor S S et al 2014 and Yacout A G et al 2012.,14

Our study shows that in Group P, the changes in mean blood glucose levels $(45.20 \%$ rise from baseline 30 minutes after intubation, $27.07 \%$ rise during $1^{\text {st }}$ hour post operatively and $11.05 \%$ rise during $2^{\text {nd }}$ hour postoperatively) co relates with studies by Yacout AG et al 2012, Gupta K et al 2013,8. In Dexmedetomidine group, though there was a significant rise $(\mathrm{p}<0.05)$ in blood glucose at 30 minutes post laryngoscopy and intubation, but it was much less than group $\mathrm{P}(9.69 \%$ versus 45.2\%; inter group $p<0.0001$ ). Dexmedetomidine produces effective attenuation of stress induced blood glucose levels by its post synaptic $\alpha 2$ agonist activity; causing a significant reduction in release of Nor epinephrine (Up to 92\%- Kallio et al 1989), ${ }^{23,24}$ thereby reducing blood glucose level. Its administration, resulting in lower levels of stress response markers (glucose, cortisol and interleukins) to surgery has been seen in studies by Yacout AG et al 2012, Gupta K et al 2013.7,8

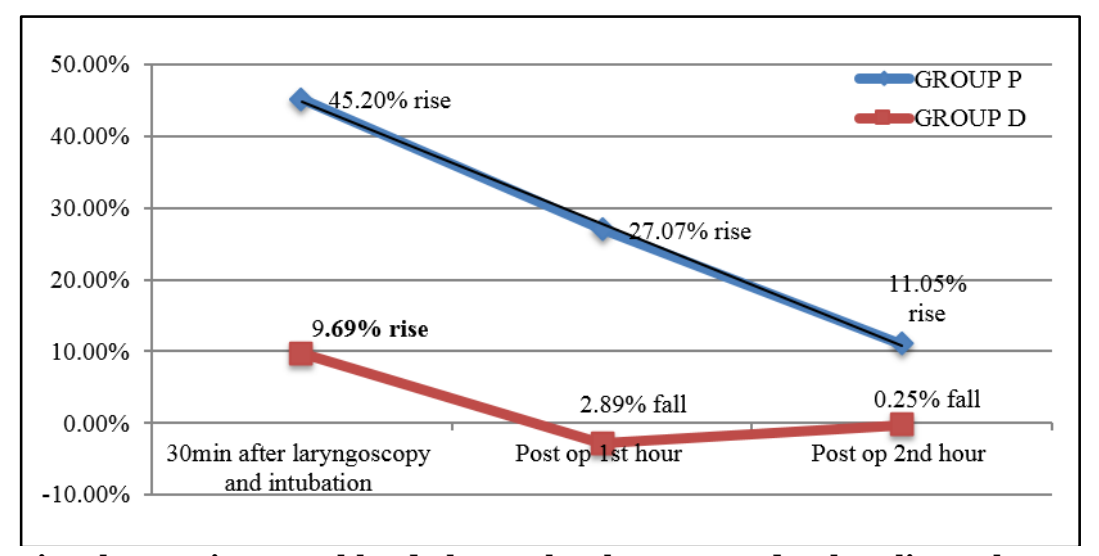

Fig. 5: Percentage wise changes in mean blood glucose levels compared to baseline values 
Yacout AG et al $2012^{7}$ demonstrated significant reduction in blood glucose $(\mathrm{mg} / \mathrm{dl})$ after recovery and $1^{\text {st }}$ day post-operatively in Dexmedetomidine group $(99.80 \pm 10.78,98.27 \pm 11.55$ in Group $\mathrm{D}$ versus $142.07 \pm 14.44$ and $132.6 \pm 30.25$ in placebo group respectively) $(\mathrm{p}<0.0001)$. Harsoor SS et al 2014, ${ }^{14}$ in a similar study found significant reduction in blood glucose levels $(\mathrm{mg} / \mathrm{dl})$ during $1^{\text {st }}$ hour post operatively in Dexmedetomidine group $(118.2 \pm 16.24)$ as compared to Placebo group (136.95 \pm 19.76) $(\mathrm{p}<0.0001)$.

Our study also showed a very highly significant reduction in hourly Sevoflurane consumption during the first and second hour in the Dexmedetomidine group as compared to the normal saline group $(\mathrm{P}<0.0001)$ $(25.61 \%$ and $21.47 \%$ in first \& second hour respectively). The hypnotic effects of Dexmedetomidine is mediated by the hyperpolarisation of nor adrenergic neurons, which suppresses neuronal firing in locus coeruleus along with inhibition of nor epinephrine release and activity in the descending medullospinal noradrenergic pathway. ${ }^{25}$ This suppression of inhibitory control triggers neurotransmitters that decrease histamine secretion producing hypnosis similar to normal sleep, without ventilatory depression. ${ }^{26}$

Khan ZP et al $1999^{27}$ showed significant MACsparing effects of Dexmedetomidine at plasma concentrations $0.35-0.75 \mathrm{ng} / \mathrm{ml}$. Harsoor SS et al $2014^{14}$ demonstrated $28 \%$ reduction in the sevoflurane requirement $(\mathrm{ml})$ in the first hour of anaesthesia $(15.45 \pm 3.97$ in Group D versus $11.10 \pm 2.17$ in placebo group). Keniya VM et al 2011 showed 32\% reduction in Isoflurane requirement in Group D compared to control group. ${ }^{22}$

The bispectral index (BIS) has previously been shown to be a quantifiable measure of sedative and hypnotic effects of anaesthetics. It analyses both Electroencephalogram (EEG) and Electromyogram (EMG) and displays values ranging 0-100. While numbers towards zero denote very deep anaesthesia, numbers close to 100 indicate that the patient is conscious. Values ranging 40-60 are considered indicative of low probability of consciousness and hence indicative of the adequacy of the depth of anaesthesia. Song et al $1997^{28}$ demonstrated 30 to $38 \%$ reduction in the consumption of volatile anaesthetics in BIS-titrated versus control group $(\mathrm{P}<0.05)$.

\section{Bi spectral index monitor}

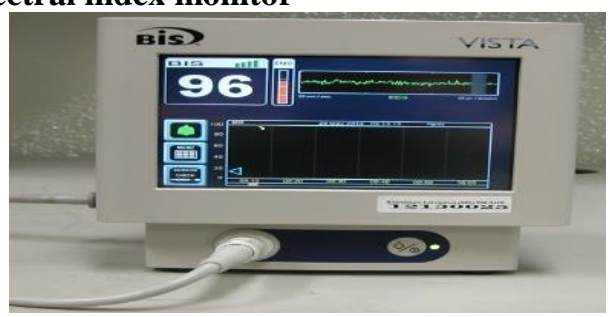

Sevoflurane consumption was measured by Dion's formula in our study. It is a simple routinely usable method, not requiring any special technology for estimation of consumed inhalation agent. ${ }^{12}$ This method as compared to Drager's algorithm has been found to underestimate the Sevoflurane consumption by $2.59 \mathrm{ml}$ with limits of agreement between $5.188 \mathrm{ml}$ and $0.008 \mathrm{ml}$ (Singh PM et al 2013). ${ }^{13}$ However, this algorithm is incorporated in Dragger Primus only and not in other lower versions. Dion's technique with slight modification for under estimation could be incorporated electronically in newer anaesthesia machines. ${ }^{13}$

Critical events like laryngoscopy and intubation, pneumoperitoneum caused significant rise in pulse rate, systolic and diastolic blood pressures in Group P in our study, while in Dexmedetomidine group, though there was minimal rise, the values were still significantly lower than baseline $(p<0.001)$. Dexmedetomidine produces its effects on the hemodynamic variables by its $\alpha-2$ agonist action on the receptors located in CNS and peripheral smooth muscle cells, leading to a decrease in nor epinephrine release. ${ }^{23,29}$

Kallio A et al 1989, Aantaa R et al 1990 demonstrated a reduction in the nor-epinephrine release upto $92 \%$ and $56 \%$ respectively with a single intravenous dose of dexmedetomidine. ${ }^{23,29}$ Patel $\mathrm{CR}$ et al 2013 demonstrated a lesser rise of pulse rate in response to intubation in Dexmedetomidine group (10\%) compared to control group (17\%) ${ }^{30}$ Berrin et al 2007 and Turan et al 2008 have similarly shown the advantageous effects of Dexmedetomidine during intubation and extubation respectively..$^{31,32}$

Hsu YW et al 2004 elicited that Dexmedetomidine, at $0.6-1.2 \mathrm{ng} / \mathrm{ml}$ plasma concentration, simulated natural sleep with intact hypercapnic ventilatory response, significant reduction in apnoea-hypopnoea index with intact hypercapnic arousal phenomenon; thereby, changes in $\mathrm{paCO}^{2}$ and minute ventilation was found comparable to baseline. ${ }^{33}$ Yacout AG et al 2012 assessed recovery profile by measuring tracheal extubation time, time to eye opening and time to following verbal commands which were longer in group D relative to group $\mathrm{P}$ but with no statistically significant difference between both groups. ${ }^{7}$ Alp Gubert et al 2006 showed tracheal extubation time and 48 hour sedation scores in Dexmedetomidine group $(0.5 \mathrm{mcg} / \mathrm{kg}$ loading dose, $1 \mathrm{mcg} / \mathrm{kg} / \mathrm{hr}$ maintenance), comparable to placebo group. ${ }^{9}$

Hall JE et al 2000, Carollo DS et al 2008 and Shukry M et al 2010, showed that omitting or halving the loading dose eliminates adverse cardiovascular effects like hypotension, bradycardia but preserves its sedative action. ${ }^{34-36}$ Basar et al 2008 and Patel C R et al 2013 have revealed no significant difference in the occurrence of adverse effects between the groups..$^{30,37}$

Other markers of the stress response to anaesthesia and surgery like Interleukin -6 and Nor-epinephrine 
could not be measured as facility for these investigations was not available in our institute or even in private labs in the city. Besides, these investigations are quite expensive ones.

\section{Conclusion}

Intravenous Dexmedetomidine given pre and intra operatively serves to be a very useful adjuvant to general anaesthesia by favourably influencing the intra operative stress induced blood glucose levels, sevoflurane requirement and hemodynamic parameters without affecting extubation time, sedation level and incidence of adverse effects.

\section{Conflicts of Interest: None.}

\section{References}

1. Kamibayashi T, Maze M. Clinical use of alpha-2 adrenergic agonists. Anesthesiol. 2000;93(5):1345-1349.

2. Khan ZP, Ferguson CN, Jones RM. Alpha -2 and imidazoline receptor agonists. Their pharmacology and Therapeutic role. Anaesth. 1999;54(2):146-165.

3. Scheinin H, Virtanen R, Mac Donald E, Lammintansta R, Scheinin M. Medetomidine - a novel alpha 2adrenoreceptor agonist: a review of its pharmacodynamic effects. Progress in neuropsycho pharmacology and Biological psychiatry. 1989;13(5):635-651.

4. Sudheesh K, Harsoor S S. Dexmedetomidine in anaesthesia practice: A wonder drug? Indian J Anaesthesiol. 2011;55:323-324.

5. Dr. Manorama Singh. Stress response and anaesthesia, altering the peri and post operative management. Indian $J$ Anaesthesiol. 2003;47(6):427-434.

6. Ivan Velickovic, Jun Yan and Jaffrey A Grass. Modifying the neuro-endocrine stress response. Seminars in Anaesthesia, Peri operative medicine and Pain. 2002;21(1):16-25.

7. Ahmed G Yacout, Hasan A Osman, Mamdouh H, AbdelDaem, Saleh A Hammouda, Mohamed M Elsawy. Effect of intravenous dexmedetomidine infusion on some pro inflammatory cytokines, stress hormones and recovery profile in major abdominal surgery. Alexandria journal of medicine, 2012;48:3-8.

8. Kumkum Gupta, Aman Maggo, Manish Jain, Prashant K Gupta, Bhawna Rastogi, Apoorva B Singhal. Blood glucose estimation as an indirect assessment of modulation of neuroendocrine stress response by dexmedetomidine versus fentanyl premedication during laparoscopic cholecystectomy: A clinical study Anaesthesia: Essays and Researches. 2013;1:(1)34-38.

9. Alp Gubert, Elif Basagan- Mongol, Gurkan Turker, Faith Ugun, F Nur Kaya, Berin Ozcan. Intraoperative infusion of dexmedetomidine reduces perioperative analgesic requirements. Canadian Journal of Anaesthesiology, 2006;53: 646-652.

10. Hsu YW, Cortinez LI, Robertson KM, Keifer JC, SumPing ST, Moretti EW, Young CC, Wright DR, Macleod DB, Somma J. Dexmedetomidine pharmacodynamics: part 2 : cross over comparison of analgesic effects of Dexmedetomidine and Remifentanyl in healthy volunteers. Anesthesiol. 2004;101(5):1077-1083.

11. Fragen RJ, Fitzgerald PC. Effect of dexmedetomidine on the minimum alveolar concentration (MAC) of sevoflurane in adults age 55 to 70 years. J Clin Anaesthesiol. 1999;11(6) 466-470.
12. Dion P. The cost of anaesthetic vapours. Can J Anaesthesiol. 1992;39:633.

13. Preet Mohinder Singh, Anjan Trikha, Renu Sinha, Anuradha Bore. Measurement of consumption of sevoflurane for short paediatric anaesthetic procedures: comparison between dion's method and dragger algorithm. J Anaesthesiol Clin Pharmacol. 2013;29(4):516-520.

14. Harsoor SS, Devika Rani D, Lathashree S, Nethra SS, Sudheesh K. Effect of intra operative Dexmedetomidine on Sevoflurane requirement and blood glucose levels during entropy guided anaesthesia. J Anaesthesiol Clin Pharmacol. 2014;30(1):25-30.

15. O'Riain SC, Buggy DJ, Kerin MJ, Watson RW, Moriarty DC. Inhibition of the stress response to breast cancer surgery by regional anesthesia and analgesia does not affect vascular endothelial growth factor and prostaglandin E2. Anesth Analg. 2005;100:244-249.

16. Asoh T, Tsuji H, Shirasaka C, Takeuchi Y. Effect of epidural analgesia on metabolic response to upper abdominal surgeries, Acta Anaesthesiol Scand. 1983;27(3):233-237.

17. Victor SB Jordan, Avery Tung. Dexmedetomidine: clinical update seminars in anesthesia. J Crit Care. 2002;21(4):265-274.

18. Ralph Gertler, H Cleighton Brown, Erin N Silvius. Dexmedetomidine: A novel sedative - analgesic agent. Proceedings (Baylor University Medical Centre), Jan 2001;14(1)13-21.

19. Aho M, Lehtinen AM, Erkola O, Kallio A, Korttila K. The effect of intravenously administered dexmedetomidine on peri operative hemodynamics and isoflurane requirements in patients undergoing abdominal hysterectomy. Anaesth. 1991;74(6):997-1002.

20. Basar H, Akpinar S, Doganci N, Buyukkocak U, Kaymak C. The effects of preanaesthetic, single-dose dexmedetomidine on induction, hemodynamic, and cardiovascular parameters. J Clin Anaesth, 2008;20(6):431-436.

21. Y.S.Lee, S.M .Wong, C.T.Hung. Dexmedetomidine infusion as a supplement to isoflurane anaesthesia for vitreo retinal surgery. Br J Anaesthesiol. 2007;98(4):477483.

22. Keniya VM, Ladi S, Naphade R. Dexmedetomidine attenuates sympathoadrenal response to tracheal intubation and reduces perioperative anaesthetic requirement. Indian J Anaesthesiol. 2011;55:352-357.

23. Kallio A, Scheinin M, Koulu M, Ponkilainen R, Ruskoaho H, Viinamäki O, Scheinin H. Clin Pharmacol Ther. 1989;46(1):33-42.

24. Bhana N, Goa KL, McClellan KJ. Dexmedetomidine, Drugs. 2000;59(2):263-8;269-270.

25. Anju Grewal. Dexmedetomidine: new avenues. $J$ Anaesthesiol Clin Pharmacol, 2011;27(3):297-302.

26. Candiotti KA, Bergese SD, Bokesch PM, Feldman MA, Wisemandle W, Bekker AY; MAC Study Group. Monitored anaesthesia care with Dexmedetomidine: a prospective, randomised, double blind multi centric trial. Anesth Analg. 2010;110(1):47-56.

27. Khan ZP, Munday IT, Jones RM, Thornton C, Mant TG, Amin D. Effects of Dexmedetomidine on Isoflurane requirements in healthy volunteers 1 : Pharmacodynamic and Pharmacokinetic considerations, Br J Anaesthesiol. 1999;83(3):372-380.

28. Song D, Joshi GP, White PF. Titration of volatile anaesthetics using bispectral index facilitates recovery after ambulatory anaesthesia. Anaesthesiol. 1997;87(4):842-848. 
29. Antaa R, Kanto J, Scheinin M, Kallio A, Scheinin H. Dexmedetomidine, an alpha 2 adrenoreceptor agonist, reduces anaesthetic requirements for patients undergoing minor gynecologic surgery. Anaesthesiol. 1990;73(2):230-235.

30. Chirag Ramanlal Patel, Smita R Engineer, Bharat J Shah, $S$ Madhu. Effect of intravenous infusion of dexmedetomidine on peri operative hemodynamic changes and post operative recovery: A study with entropy analysis. J Anaesthesiol Clin Pharmacol. 2013;29(3):318-322.

31. Berrin Isik, Mustafa Arslan, Ozgur Ozsoylar, Mehmet Akcabay. The effects of alpha- 2 adrenoreceptor agonist dexmedetomidine on hemodynamic response in direct laryngoscopy. Open Otorhinolaryngol J. 2007;1:5-11.

32. Turan G, Ozgultekin A, Turan C, Dincer E, Yuksel G. Advantageous effects of Dexmedetomidine on haemodynamic and recovery responses during extubation for intracranial surgery. Eur J Anaesthesiol. 2008;25(10):816-820.

33. Hsu YW, Cortinez LI, Robertson KM, Keifer JC, SumPing ST, Moretti EW, Young CC, Wright DR, Macleod DB, Somma J. Dexmedetomidine pharmacodynamics: part $1:$ cross over comparison of respiratory effects of Dexmedetomidine and Remifentanyl in healthy volunteers. Anesthesiol. 2004;101(5):1066-76.
34. Hall JE, Uhrich TD, Barney JA.- Sedative, amnestic, and analgesic properties of small-dose dexmedetomidine infusions. Anesth Analg, 2000;90:699-705.

35. Carollo DS, Nossaman BD, Ramadhyani U.

Dexmedetomidine: a review of clinical applications. Curr Opin Anaesthesiol. 2008;21(4):457-461.

36. Shukry M, Miller JA. Update on Dexmedetomidine: use in nonintubated patients requiring sedation for surgical procedures. J Ther Clin Risk Manag. 6:111-121.

37. Basar

H, Akpinar S, Doganci N, Buyukkocak U, Kaymak C. Th e effects of preanaesthetic, single-dose dexmedetomidine on induction, hemodynamic, and cardiovascular parameters. J Clin Anaesth, 2008;20(6):431-436.

How to cite this article: Kameshwar Y V, Upadhyay M R. Effect of dexmedetomidine infusion on stress induced blood glucose levels and intraoperative sevoflurane requirement. Indian $\mathrm{J}$ Clin Anaesth. 2018;5(4):582-590. 